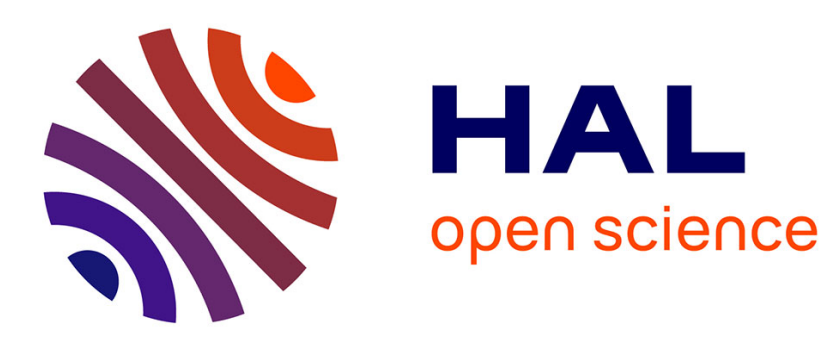

\title{
Stiffening of nanoscale anatase TiZrO upon multiple compression cycles
}

\author{
E. Holbig, L. S. Dubrovinsky, V. Swamy, R. Wirth, V. Prakapenka, A.
}

Kuznetsov

\section{- To cite this version:}

E. Holbig, L. S. Dubrovinsky, V. Swamy, R. Wirth, V. Prakapenka, et al.. Stiffening of nanoscale anatase TiZrO upon multiple compression cycles. Journal of Physics and Chemistry of Solids, 2009, 69 (9), pp.2230. 10.1016/j.jpcs.2008.04.022 . hal-00560688

\section{HAL Id: hal-00560688 \\ https://hal.science/hal-00560688}

Submitted on 29 Jan 2011

HAL is a multi-disciplinary open access archive for the deposit and dissemination of scientific research documents, whether they are published or not. The documents may come from teaching and research institutions in France or abroad, or from public or private research centers.
L'archive ouverte pluridisciplinaire HAL, est destinée au dépôt et à la diffusion de documents scientifiques de niveau recherche, publiés ou non, émanant des établissements d'enseignement et de recherche français ou étrangers, des laboratoires publics ou privés. 


\section{Author's Accepted Manuscript}

Stiffening of nanoscale anatase $\mathrm{Ti}_{0.9} \mathrm{Zr}_{0.1} \mathrm{O}_{2}$ upon multiple compression cycles

E. Holbig, L. Dubrovinsky, V. Swamy, R. Wirth, V. Prakapenka, A. Kuznetsov

PII: $\quad$ S0022-3697(08)00110-8

DOI: $\quad$ doi:10.1016/j.jpcs.2008.04.022

Reference: $\quad$ PCS 5441

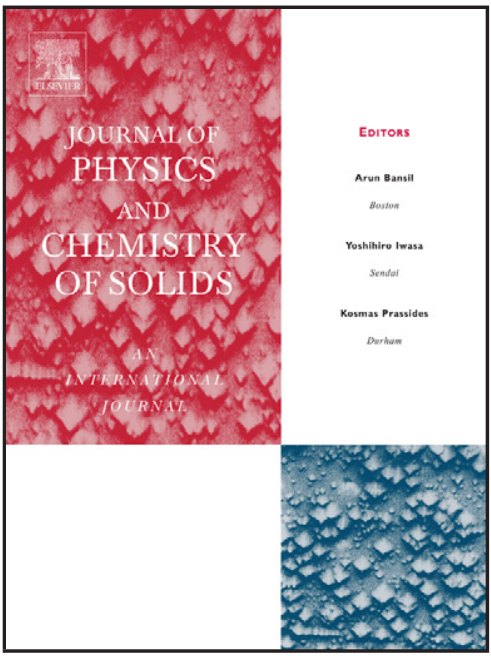

www.elsevier.com/locate/jpcs

To appear in: Journal of Physics and Chemistry of Solids

Cite this article as: E. Holbig, L. Dubrovinsky, V. Swamy, R. Wirth, V. Prakapenka and A. Kuznetsov, Stiffening of nanoscale anatase $\mathrm{Ti}_{0.9} \mathrm{Zr}_{0.1} \mathrm{O}_{2}$ upon multiple compression cycles, Journal of Physics and Chemistry of Solids (2008), doi:10.1016/j.jpcs.2008.04.022

This is a PDF file of an unedited manuscript that has been accepted for publication. As a service to our customers we are providing this early version of the manuscript. The manuscript will undergo copyediting, typesetting, and review of the resulting galley proof before it is published in its final citable form. Please note that during the production process errors may be discovered which could affect the content, and all legal disclaimers that apply to the journal pertain. 
Stiffening of nanoscale anatase $\mathrm{Ti}_{0.9} \mathrm{Zr}_{0.1} \mathrm{O}_{2}$ upon multiple compression
cycles E. Holbig ${ }^{a^{*}}$, L. Dubrovinsky ${ }^{a}$, V. Swamy ${ }^{b}$, R. Wirth ${ }^{\mathrm{c}}$, V. Prakapenka $^{\mathrm{d}}$ and A. Kuznetsov ${ }^{\mathrm{d}}$ ${ }^{a}$ Bayerisches Geoinstitut, University of Bayreuth, D-95440 Bayreuth, Germany

${ }^{\mathrm{b}}$ Department of Materials Engineering, Monash University, P.O. Box 69M, Victoria 3800, Australia

${ }^{\mathrm{c}}$ Geoforschungszentrum Potsdam, D-14473 Potsdam, Germany

${ }^{\mathrm{d}}$ GeoSoilEnviroCARS, University of Chicago, Chicago, 60637, USA

\begin{abstract}
The compression behavior of nanoscale Zr-doped anatase was studied by means of a diamond anvil cell experiment with alternating cycles of compression and decompression in the stability field of anatase (up to $13 \mathrm{GPa}$ ). We found that multiple cycles of compression lead to stiffening of the material: Precompressed samples of nanoanatase $\mathrm{Ti}_{0.9} \mathrm{Zr}_{0.1} \mathrm{O}_{2}$ have a higher bulk modulus $\left(\mathrm{K}_{0}=249(9)\right.$ and 266(6) GPa) compared to the sample when compressed for the first time $\left(\mathrm{K}_{0}=211(7) \mathrm{GPa}\right)$. Upon compression, the crystallite size remains the same and the crystalline areas are free of defects. After the experiment, the crystallites are surrounded by amorphous rims, confirming the theoretical prediction by Pischedda et al. [1] for nanoscale anatase, but yielding much lower pressures $(12 \mathrm{GPa})$ for the onset of partial amorphization.
\end{abstract}

Keywords: A. oxides, A. nanostructures, D. elastic properties, D. equation of state, D. mechanical properties

*Correspnding author

Phone: +49-921-553878, Fax: +49-921-553769, email: Eva.Holbig@uni-bayreuth.de 


\section{Introduction}

Anatase $\mathrm{TiO}_{2}$ in the macrocrystalline and nanocrystalline form is widely used as material in pigments, plastics, cosmetics, electronics, and catalysts industries. It is a wide band-gap semiconductor used for electrochemical dye solar cells [2] and exhibits a good performance in photocatalysis $[3,4]$. For all technical applications, the microstructure of the material is an important tool for tuning the properties and among the materials used one can find thin films as well as mesopouros, nanocrystalline or polycrystalline materials. The crystallite size has a strong effect on the relative stability of anatase and other $\mathrm{TiO}_{2}$ modifications like rutile, brookite or high pressure polymorphs $\mathrm{TiO}_{2} \mathrm{II}$ and $\mathrm{MI}$ phase [1,5-7]. Nanoscale anatase remains stable to much higher pressures compared to the microcrystalline or single crystal counterpart [8] and when the crystallite size is smaller than the critical value of $\sim 10 \mathrm{~nm}$, pressure induced amorphization takes place at pressures of $\sim 20$ to $24 \mathrm{GPa}[7]$.

The bulk modulus of anatase varies strongly with the crystallite size of the starting material and also in response to doping with Zr. In former studies using the diamond anvil cell apparatus (DAC) and synchrotron powder X-ray diffraction (XRD) the authors fitted experimental pressure-volume data to the second-order BirchMurnaghan Equation of State $(\mathrm{EoS})$ and determined $\mathrm{K}_{0}=178(1) \mathrm{GPa}$ [9] and $\mathrm{K}_{0}=$ $190(10) \mathrm{GPa}$ [10] for the bulk modulus of microscale anatase $\mathrm{TiO}_{2}$. In comparison, the values for nanoscale anatase are much higher with $\mathrm{K}_{0}=243(3) \mathrm{GPa}$ [8] and $\mathrm{K}_{0}=237(3)$ GPa [1]. The data suggest that anatase becomes stiffer when the crystallite size is decreased to the nanometer scale. Additionally, doping with $\mathrm{Zr}$ of nanoscale anatase leads to an even higher bulk modulus of $\mathrm{K}_{0}=266(6) \mathrm{GPa}$ for $\mathrm{Ti}_{0.9} \mathrm{Zr}_{0.1} \mathrm{O}_{2}$ [11]. The fact that $\mathrm{Zr}$ doping of nanoanatase produces the least compressible form of anatase is opposite to the expectation from the comparison of elastic constants for $\mathrm{TiO}_{2}$ and $\mathrm{ZrO}_{2}$ polymorphs. While $\mathrm{ZrO}_{2}$ polymorphs show a smaller bulk modulus than the corresponding $\mathrm{TiO}_{2}$ forms, the incorporation of $\mathrm{Zr}$ into $\mathrm{TiO}_{2}$ anatase results in an increasing bulk modulus. Furthermore, the compression behavior of $\mathrm{Zr}$-doped nanoanatase $\mathrm{Ti}_{0.9} \mathrm{Zr}_{0.1} \mathrm{O}_{2}$ shows another interesting phenomenon. Analysis of the X-ray diffraction data shows a significant change in compression behavior at pressures $>4 \mathrm{GPa}$. The slope of the ratio of lattice parameters $a / c$ strongly increases, the slope of the ratio of the apical and equatorial bond length of the octahedra changes from negative to positive, and the z-coordinate of the oxygen atom, the only free atomic coordinate, changes its trend [11]. The authors suggested that the anomalous compression behavior of the sample is related to the 
nanocrystallinity and proposed that $\mathrm{Zr}$-doping and the tendency of clustering of Zr-atoms could affect the structural parameters and influence the elastic properties.

In order to study these phenomena in more detail and to find out, whether the pressure induced changes of structural parameters are reversible upon decompression, we carried out DAC experiments on anatase $\mathrm{Ti}_{0.9} \mathrm{Zr}_{0.1} \mathrm{O}_{2}$ with crystallite size of $\sim 12 \mathrm{~nm}$, performing multiple cycles of compression and decompression within the stability field of the material, which is up to $13 \mathrm{GPa}$.

\section{Experimental method}

Experiments on a mixture of nanoscale anatase $\mathrm{Ti}_{0.9} \mathrm{Zr}_{0.1} \mathrm{O}_{2}$ and $\mathrm{LiF}$ were carried out in the diamond anvil cell, at the synchrotron facility GeoSoilEnviroCARS 13 IDD at the Advanced Photon Source (APS), Argonne, Illinois; details of the experimental setup, starting material and XRD data processing are as in ref. [11]. An X-ray beam with a wavelength of $0.3344 \AA$ and a size of $6 \times 15 \mu \mathrm{m}$ was used. The distance sample to detector was $201 \mathrm{~mm}$. The seats of the DAC were made from $\mathrm{cBN}$ and allowed the collection of diffraction data to $d=1 \AA$. Unlike other DAC samples [11], the sample was loaded without any compression applied during the loading process, then compressed at room temperature to $12 \mathrm{GPa}$, decompressed to $0.5 \mathrm{GPa}$, compressed to $12 \mathrm{GPa}$ and decompressed to ambient conditions.

In order to prepare a quenched sample to be observed by TEM, a second experiment with the same setup of the DAC was performed on the pure Zr-doped nanoanatase, using Raman spectroscopy. The material was loaded together with a small ruby-sphere, and sample pressures were determined from the pressure dependent shift of the ruby fluorescence $\mathrm{R}_{1}$ line [12]. The pressure-induced frequency shifts were monitored while the sample was compressed and decompressed in the same way as the previous experiment. After the experiment, the sample was prepared for TEM analysis, using a FEI FIB200TEM Focused Ion Beam (FIB) device [13]. The produced foil with a thickness of $\sim 50 \mathrm{~nm}$ was analyzed at the FEI Tecnai ${ }^{\mathrm{TM}} \mathrm{G}^{2}$ F20 X-Twin transmission electron microscope at the GeoForschungszentrum, Potsdam. The crystallite size of the doped anatase was measured before and after the experiment, using high-resolution TEM and convolution-based profile fitting of XRD data. 


\section{Results and discussion}

The lattice parameters of Zr-doped nanoscale anatase at zero pressure were refined to $a=3.8110(3), c=9.6101(12) \AA$ and $V=139.57(2) \AA^{3}$. Tab. 1 presents refined lattice parameters of anatase and $\mathrm{LiF}$ as well as the pressure, Fig. 1 shows representative results of full profile refinements at low and high pressures, indicating the high quality of the fit.

Fig. 2 shows the pressure-volume data of the sample as refined from XRD data and results of the fitting to a second order EoS with the first derivative of the bulk modulus, $\mathrm{K}_{0}$ ' fixed to 4 . The bulk modulus of the material was determined during the first compression to $\mathrm{K}_{0}=211(7) \mathrm{GPa}$, upon the decompression the bulk modulus was decreased to $\mathrm{K}_{0}=199(3) \mathrm{GPa}$ and it was increased upon the second compression to $\mathrm{K}_{0}=$ 249 (9) GPa. The results show that the precompressed sample is stiffer compared to the uncompressed sample. The figure also shows the data of the previous experiment performed on the same material, described by Holbig et al. [11]. It is worth noting at this point that the experiment Holbig et al. [11] was performed on a sample which was compacted and precompressed between diamond anvils during the sample loading. The bulk modulus was measured as $\mathrm{K}_{0}=266(6) \mathrm{GPa}$, confirming the hypothesis that precompressed samples are stiffer than originally uncompressed samples.

Fig. 3 presents the values of the ratio of lattice parameters $a / c$ as a function of the pressure. The slope of the curve is linear for the first compression and more or less also for the decompression. Upon the second compression however, the slope becomes steeper at pressure $>5 \mathrm{GPa}$, which is comparable to the results reported by Holbig et al. [11] (line 3' in Fig. 2). The anomalous compression behavior for nanoscale Zr-doped anatase reported before is therefore reproduced in this study.

The XRD data of the sample at ambient conditions at the beginning (a) and at the end (b) of the experiment were used to estimate the crystallite size and to see, whether a change of the microstructure can be observed. We used the TOPAS-ACADEMIC software [14] for convolution-based profile fitting [15] and refined the microstructure. The source emission profile and instrumental contribution to peak broadening were determined by means of the diffraction spectrum of a $\mathrm{CeO}$ standard. The effects of crystallite size and strain on the peak broadening were analyzed using the double-Voigt approach [16] and the maximum (upper limit) strain values $e_{0}$ as well as the integralbreadth based volume-weighted mean column height $L_{V o l} I B$ of coherently diffracting domains [15] were obtained simultaneously. The estimate of crystallite size from $L_{V o l} I B$ depends on the shape and the size distribution of the crystallites. For monodisperse 
spherical crystallites with diameter $\mathrm{D}$, the following equation is applicable: $\mathrm{D}=4 / 3 \mathrm{~L}_{\mathrm{Vol}}$ $I B .[17,18]$ The strain of the material increased strongly during the experiment from $e_{0}=$ $0.13(3) \%$ at the beginning to $0.26(4) \%$ at the end. The crystallite size appears bigger at the end of the experiment but we attest no physical meaning to it. We suggest that the increasing strain slightly biases towards itself the relative contributions to the peak broadening due to a reduced data quality for $b$ ). Another confirmation of the additionally induced strain is the relationship between $a$ and $c$ lattice parameters (table 2). The unit cell at the end of the experiment is deformed with an elongation of the $a$ parameter and shortening of the $b$ parameter. At the same time the unit cell volume and pressure are practically the same.

Fig. 4 shows high-resolution TEM images of the starting material as well as the quenched sample of the second experiment, performed on pure anatase $\mathrm{Ti}_{0.90} \mathrm{Zr}_{0.10} \mathrm{O}_{2}$. The crystallite sizes are $12( \pm 3) \mathrm{nm}$ for both samples and therefore remain more or less constant during the experiment. The crystallites of the quenched sample show spherical crystal shape and are defect free. There are several lines of evidence suggesting that the crystallites are surrounded by amorphous rims and that amorphization takes place gradually upon compression. Pressure induced amorphization was observed before by Swamy et al. [7], who claimed that anatase with crystallite size of $<10 \mathrm{~nm}$ transforms upon compression to a high density amorphous phase, which transforms to a low density amorphous phase upon the quenching process. In contrast, coarser samples undergo transformations to crystalline high pressure polymorphs. Partial amorphization was suggested earlier for experimental studies (e.g. [1]), but could not be detected by the insitu XRD analysis because the broad amorphous features would be hidden in the background signal - a phenomenon that applies also for this study. Partial amorphization was theoretically predicted by Pischedda et al. [1], who performed molecular dynamics computations, using a simple Buckingham potential and computed compression of a single anatase nanoparticle in a box of $10 \mathrm{~nm}$ dimension in excess of the nanoparticle volume. At $25 \mathrm{GPa}$, the simulations suggest the appearance of disorder in the surfaceshell region (about $30-40 \%$ of the atoms), surrounding a more rigid crystalline core, which also contains some defects. In our study, the TEM analysis of the material after compression shows in fact features that can be assigned as rims of amorphous material with a thickness of several nanometer (Fig. 4, right), confirming the suggested appearance of partial amorphization. However, the TEM image shows a part of the sample where several crystallites overlap and the features seen could be the consequence of that. To avoid overlap of crystallites, TEM foils with a thickness of 10-15 nm would be necessary. 
The lines of evidence described lead us to the conclusion that the nanoscale anatase $\mathrm{Ti}_{0.9} \mathrm{Zr}_{0.1} \mathrm{O}_{2}$ undergoes partial pressure induced amorphization, which leads to stiffening of the material. Upon compression, amorphous rims start to envelop the crystallites. The amorphization takes place gradually and starts at much lower pressures than predicted theoretically (12 $\mathrm{GPa}$ as opposed to $25 \mathrm{GPa}$ [1]). We can use the phenomenon of amorphization to explain the compression behavior of the sample in the following way: Part of the compression energy is used for the formation of amorphous crystallite rims. The rims seem to shield the anatase particles against pressure change and most probably deform and exhibit strain while they are assimilating the compression energy. The anatase nanocrystallites therefore undergo less pressure change than the LiF particles. The partial amorphization is accompanied by a stiffening of the material, making it an interesting phenomenon for material research with the goal to create new abrasive materials.

\section{Acknowledgments}

We want to thank S. Saxena for the organization of the SMEC conference and N. Miyashima for TEM analysis of the starting material. This work was supported by the Elitenetzwerk Bayern of the state of Bavaria, Germany. GeoSoilEnviroCARS is supported by the National Science Foundation - Earth Sciences (EAR-0217473), Department of Energy - Geosciences (DE-FG02-94ER14466) and the State of Illinois. Use of the APS was supported by the U.S. Department of Energy, Office of Science, Office of Basic Energy Sciences, under Contract No. W-31-109-ENG-38. 


\section{References}

[1] V. Pischedda, G.R. Hearne, A.M. Dawe, J.E. Lowther, Ultrastability and enhanced stiffness of similar to $6 \mathrm{~nm} \mathrm{TiO}$ nanoanatase and eventual pressureinduced disorder on the nanometer scale, Phys. Rev. Let. 96 (2006) 035509.

[2] U. Bach, D. Lupo, P. Comte, J.E. Moser, F. Weissortel, J. Salbeck, H. Spreitzer, M. Gratzel, Solid-state dye-sensitized mesoporous $\mathrm{TiO}_{2}$ solar cells with high photon-to-electron conversion efficiencies, Nature 395 (1998) 583-585.

[3] M.R. Hoffmann, S.T. Martin, W.Y. Choi, D.W. Bahnemann, Environmental Applications of Semiconductor Photocatalysis, Chem. Rev. 95 (1995) 69-96.

[4] M.A. Fox, M.T. Dulay, Heterogeneous Photocatalysis, Chem. Rev. 93 (1993) 341-357.

[5] J.F. Banfield, B.L. Bischoff, M.A. Anderson, $\mathrm{TiO}_{2}$ Accessory Minerals Coarsening, and Transformation Kinetics in Pure and Doped Synthetic Nanocrystalline Materials, Chem. Geol. 110 (1993) 211-231.

[6] M.R. Ranade, A. Navrotsky, H.Z. Zhang, J.F. Banfield, S.H. Elder, A.Zaban, P.H. Borse, S.K. Kulkarni, G.S. Doran, H.J. Whitfield, Energetics of nanocrystalline $\mathrm{TiO}_{2}$, Proceedings of the National Academy of Sciences of the United States of America 99 (2002) 6476-6481.

[7] V. Swamy, A. Kuznetsov, L.S. Dubrovinsky, P.F. McMillan, V.B. Prakapenka, G. Shen, B.C. Muddle, Size-dependent pressure-induced amorphization in nanoscale $\mathrm{TiO}_{2}$, Phys. Rev. Let. 96 (2006) 135702.

[8] V. Swamy, L.S. Dubrovinsky, N.A. Dubrovinskaia, A.S. Simionovici, M. Drakopoulos, V. Dmitriev, H.P. Weber, Compression behavior of nanocrystalline anatase $\mathrm{TiO}_{2}$, Solid State Comm. 125 (2003) 111-115.

[9] V. Swamy, L.S. Dubrovinsky, Bulk modulus of anatase, J. Phys. Chem. Sol. 62 (2001) 673-675.

[10] T. Arlt, M. Bermejo, M.A. Blanco, L. Gerward, J.Z. Jiang, J.S. Olsen, J.M. Recio, High-pressure polymorphs of anatase $\mathrm{TiO}_{2}$, Phys. Rev. B 61 (2000) 14414-14419.

[11] E. Holbig, L. Dubrovinsky, G. Steinle-Neumann, V. Prakapenka, V. Swamy, Compression behavior of Zr-doped nanoanatase, Zeitschrift Naturforsch. B - J. Chem. Sci. 61 (2006) 1577-1585.

[12] H.K. Mao, J. Xu, P.M. Bell, Calibration of the Ruby Pressure Gauge to 800-Kbar under Quasi-Hydrostatic Conditions, J. Geophys. Res. -Solid Earth and Planets 91 (1986) 4673-4676.

[13] R. Wirth, Focused ion beam (FIB): Applications in micro- and nanoanalysis in geosciences and applied mineralogy, Praktische Metallographie-Practical Metallography 42 (2005) 188-205.

[14] S.L. Yang, J.M. Wu, $\mathrm{ZrO}_{2}-\mathrm{TiO}_{2}$, Ceramic Humidity Sensors, J. Mat. Sci. 26 (1991) 631-636.

[15] D.P. Xu, X.Y. Guo, S.E. Liu, Q.Y. Wang, W.H. Su, Influence of high pressure and high temperature on the structure of $\mathrm{ZrO}_{2}$ nanosolids, J. Phys.-Condensed Mat. 14 (2002) 11203-11207.

[16] D. Balzar, H. Ledbetter, Voigt-Function Modeling in Fourier-Analysis of SizeBroadened and Strain-Broadened X-Ray-Diffraction Peaks, J. Appl. Cryst. 26 (1993) 97-103.

[17] N.C. Popa, D. Balzar, An analytical approximation for a size-broadened profile 
given by the lognormal and gamma distributions, J. Appl. Cryst. 35 (2002) 338346.

[18] D. Balzar, Profile Fitting of X-Ray-Diffraction Lines and Fourier-Analysis of Broadening, J. Appl. Cryst. 25 (1992) 559-570. 
Tab. 1. Experimental lattice parameters and pressures

\begin{tabular}{|c|c|c|c|c|c|c|}
\hline Exp. & $\begin{array}{l}\text { Anatase } \\
a(\AA)\end{array}$ & $c(\AA)$ & $V\left(\AA^{3}\right)$ & $\begin{array}{l}\mathrm{LiF} \\
a(\AA)\end{array}$ & $V\left(\AA^{3}\right)$ & $p$ (GPa) \\
\hline 1 & $3.801(1)$ & $9.583(4)$ & $138.45(6)$ & $4.031(1)$ & $65.47(1)$ & $0.3(1)$ \\
\hline 2 & $3.800(1)$ & $9.583(4)$ & $138.39(7)$ & $4.030(1)$ & $65.46(1)$ & $0.3(1)$ \\
\hline 3 & $3.800(1)$ & $9.583(5)$ & $138.35(8)$ & $4.030(1)$ & $65.46(2)$ & $0.3(1)$ \\
\hline 4 & $3.799(2)$ & $9.577(1)$ & $138.20(20)$ & $4.003(1)$ & $64.14(1)$ & $1.9(1)$ \\
\hline 5 & $3.794(1)$ & $9.544(6)$ & $137.35(10)$ & $3.988(1)$ & $63.44(1)$ & $2.8(2)$ \\
\hline 6 & $3.790(2)$ & $9.528(11)$ & $136.86(18)$ & $3.964(1)$ & $62.28(1)$ & $4.0(3)$ \\
\hline 7 & $3.784(1)$ & $9.493(8)$ & $135.89(14)$ & $3.946(1)$ & $61.42(1)$ & $5.7(3)$ \\
\hline 8 & $3.778(2)$ & $9.465(11)$ & $135.11(19)$ & $3.924(1)$ & $60.43(1)$ & $7.3(4)$ \\
\hline 9 & $3.770(1)$ & $9.411(6)$ & $133.79(10)$ & $3.904(1)$ & $59.49(1)$ & $8.9(4)$ \\
\hline 10 & $3.767(2)$ & $9.393(9)$ & $133.29(15)$ & $3.887(1)$ & $58.75(1)$ & $10.3(5)$ \\
\hline 11 & $3.762(2)$ & $9.368(14)$ & $132.57(23)$ & $3.873(1)$ & $58.09(1)$ & $11.6(5)$ \\
\hline 12 & $3.761(2)$ & $9.339(9)$ & $132.09(14)$ & $3.872(1)$ & $58.05(1)$ & $11.7(5)$ \\
\hline 13 & $3.761(1)$ & $9.343(7)$ & $132.15(11)$ & $3.880(1)$ & $58.42(1)$ & $10.9(5)$ \\
\hline 14 & $3.761(1)$ & $9.347(6)$ & $132.24(9)$ & $3.885(1)$ & $58.62(1)$ & $10.6(5)$ \\
\hline 15 & $3.763(1)$ & $9.347(7)$ & $132.37(11)$ & $3.893(1)$ & $59.00(1)$ & $9.8(4)$ \\
\hline 16 & $3.768(1)$ & $9.393(8)$ & $133.37(13)$ & $3.917(1)$ & $60.11(1)$ & $7.8(4)$ \\
\hline 17 & $3.770(1)$ & $9.397(8)$ & $133.52(13)$ & $3.919(1)$ & $60.17(1)$ & $7.7(4)$ \\
\hline 18 & $3.772(1)$ & $9.410(6)$ & $133.87(11)$ & $3.926(1)$ & $60.53(1)$ & $7.1(4)$ \\
\hline 19 & $3.777(1)$ & $9.447(7)$ & $134.75(12)$ & $3.946(4)$ & $61.46(1)$ & $5.6(3)$ \\
\hline 21 & $3.781(1)$ & $9.473(7)$ & $135.40(12)$ & $3.960(5)$ & $62.10(1)$ & $4.6(3)$ \\
\hline 22 & $3.783(1)$ & $9.490(6)$ & $135.80(10)$ & $3.9732(6)$ & $62.72(2)$ & $3.8(2)$ \\
\hline 23 & $3.800(1)$ & $9.556(5)$ & $137.96(8)$ & $4.024(1)$ & $65.17(2)$ & $0.6(1)$ \\
\hline 24 & $3.798(1)$ & $9.550(7)$ & $137.73(12)$ & $3.982(1)$ & $63.13(1)$ & $3.2(2)$ \\
\hline 25 & $3.793(1)$ & $9.521(5)$ & $136.95(8)$ & $3.959(4)$ & $62.06(1)$ & $4.7(3)$ \\
\hline 26 & $3.787(8)$ & $9.494(5)$ & $136.14(8)$ & $3.933(1)$ & $60.83(2)$ & $6.6(3)$ \\
\hline 27 & $3.780(1)$ & $9.462(6)$ & $135.18(10)$ & $3.909(1)$ & $59.72(2)$ & $8.5(4)$ \\
\hline 28 & $3.771(1)$ & $9.417(6)$ & $133.88(9)$ & $3.880(1)$ & $58.40(2)$ & $11.0(5)$ \\
\hline 29 & $3.803(1)$ & $9.567(3)$ & $138.36(6)$ & $4.026(1)$ & $65.25(1)$ & $0.5(1)$ \\
\hline
\end{tabular}


Tab. 2. Results of convolution-based profile fitting

\begin{tabular}{|l|l|l|l|l|l|l|l|l|}
\hline & $p(\mathrm{GPa})$ & $V\left(\AA^{3}\right)$ & $a(\AA)$ & $c(\AA)$ & $\mathrm{L}_{\text {Vol IB }}(\mathrm{nm})$ & $\mathrm{D}(\mathrm{nm})$ & $\mathrm{e}_{0}(\%)$ & $\mathrm{Rwp}$ \\
\hline $\mathrm{a}$ & 0.29 & $138.30(4)$ & $3.7998(4)$ & $9.578(2)$ & $8.2(4)$ & $10.9(6)$ & $0.13(3)$ & 8.6 \\
\hline $\mathrm{b}$ & 0.52 & $138.22(5)$ & $3.8017(4)$ & $9.563(3)$ & $9.3(6)$ & $12.4(1)$ & $0.26(4)$ & 9.1 \\
\hline
\end{tabular}

$\mathrm{a}=$ at the beginning, $\mathrm{b}=$ at the end of the experiment; 


\section{Figure captions}

Fig. 1. Results of full profile refinements of XRD patterns at various pressures on the first compression (upper and middle) and after the second decompression (lower). $\lambda=0.3344 \AA$; upper tickmarks $=\mathrm{LiF}$; lower tickmarks $=$ anatase $\mathrm{Zr}_{0.1} \mathrm{Ti}_{0.9} \mathrm{O}_{2}$.

Fig. 2. Experimental room temperature pressure-volume data of nano crystalline $\mathrm{Zr}_{0.1} \mathrm{Ti}_{0.9} \mathrm{O}_{2}$ anatase of this study (diamonds) and the study of Holbig et al., 2006 [11] on a precompressed sample (crosses). Curves show the fit to a second order BirchMurnaghan equation of state with $\mathrm{K}_{0}{ }^{\prime}=4$. 1. The black curve (1) shows the first compression, the dark grey curve (2) shows the first decompression, the light grey curve (3) indicates the second compression. The diamond (open symbol) is from the second decompression. Crosses and the light grey curve (3') are from the second compression of a sample from Holbig et al. [11].

Fig. 3. Ratio of the lattice parameters $a / c$ of nanocrystalline $\mathrm{Zr}_{0.1} \mathrm{Ti}_{0.9} \mathrm{O}_{2}$ anatase. Symbols as in Fig. 2.

Fig. 4. High-resolution TEM image of the starting material $\mathrm{Zr}_{0.1} \mathrm{Ti}_{0.9} \mathrm{O}_{2}$ anatase (left) and the sample after the experiment (right). Both images indicate average crystallite sizes of 12- $\pm-n m$. C marks a crystalline area, A marks the suggested amorphous rim. 
Fig. 1

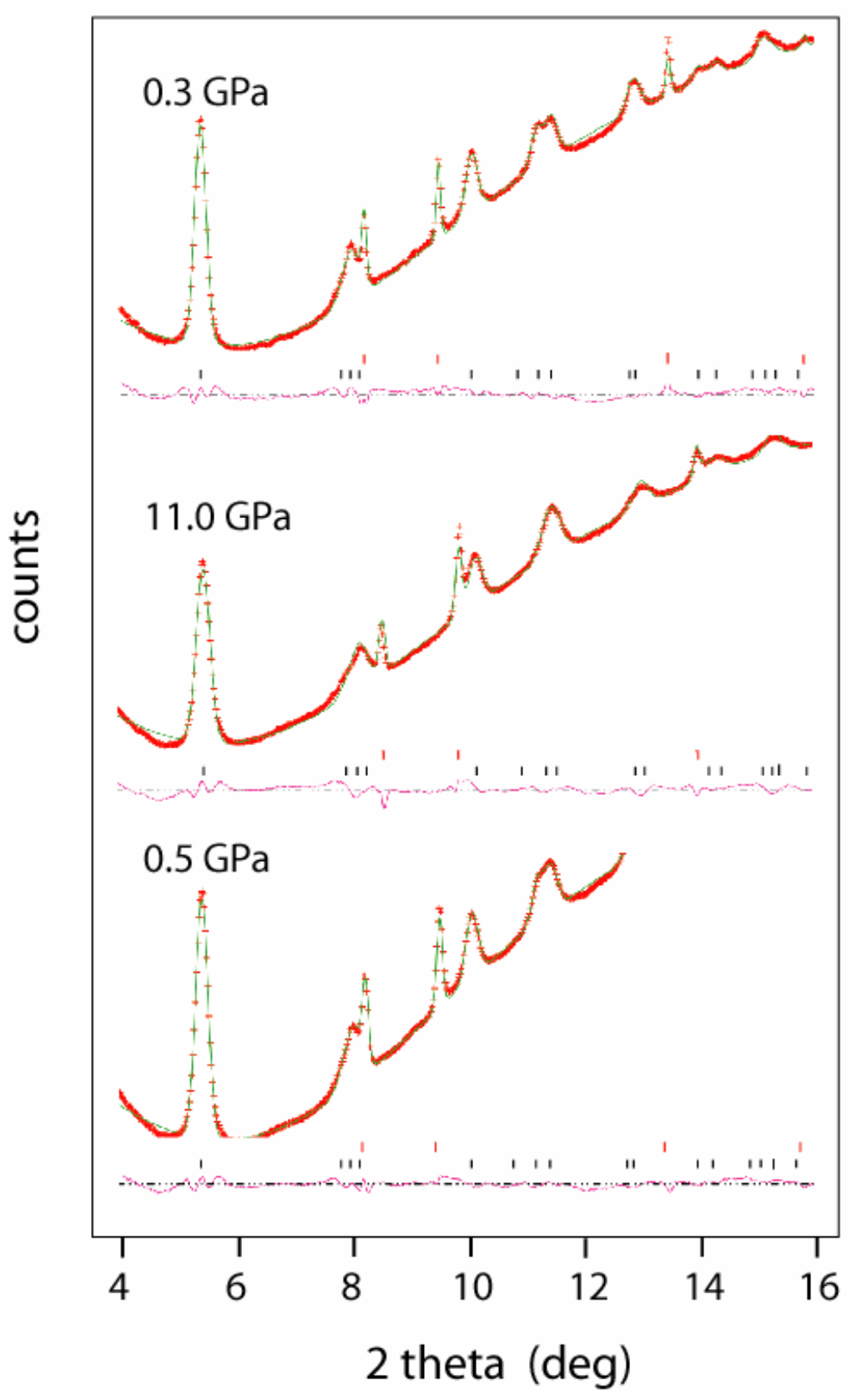


Fig. 2.

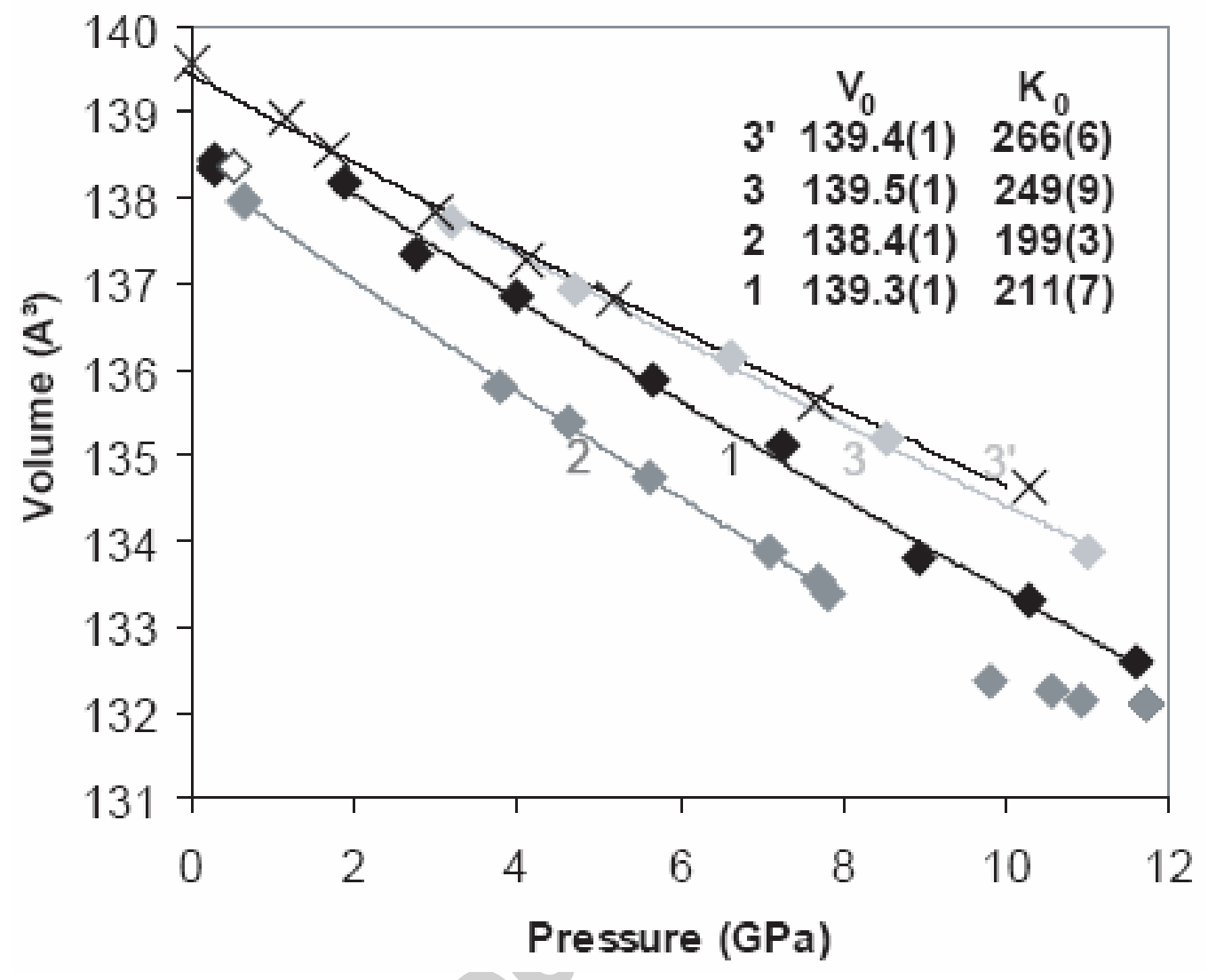


Fig. 3.

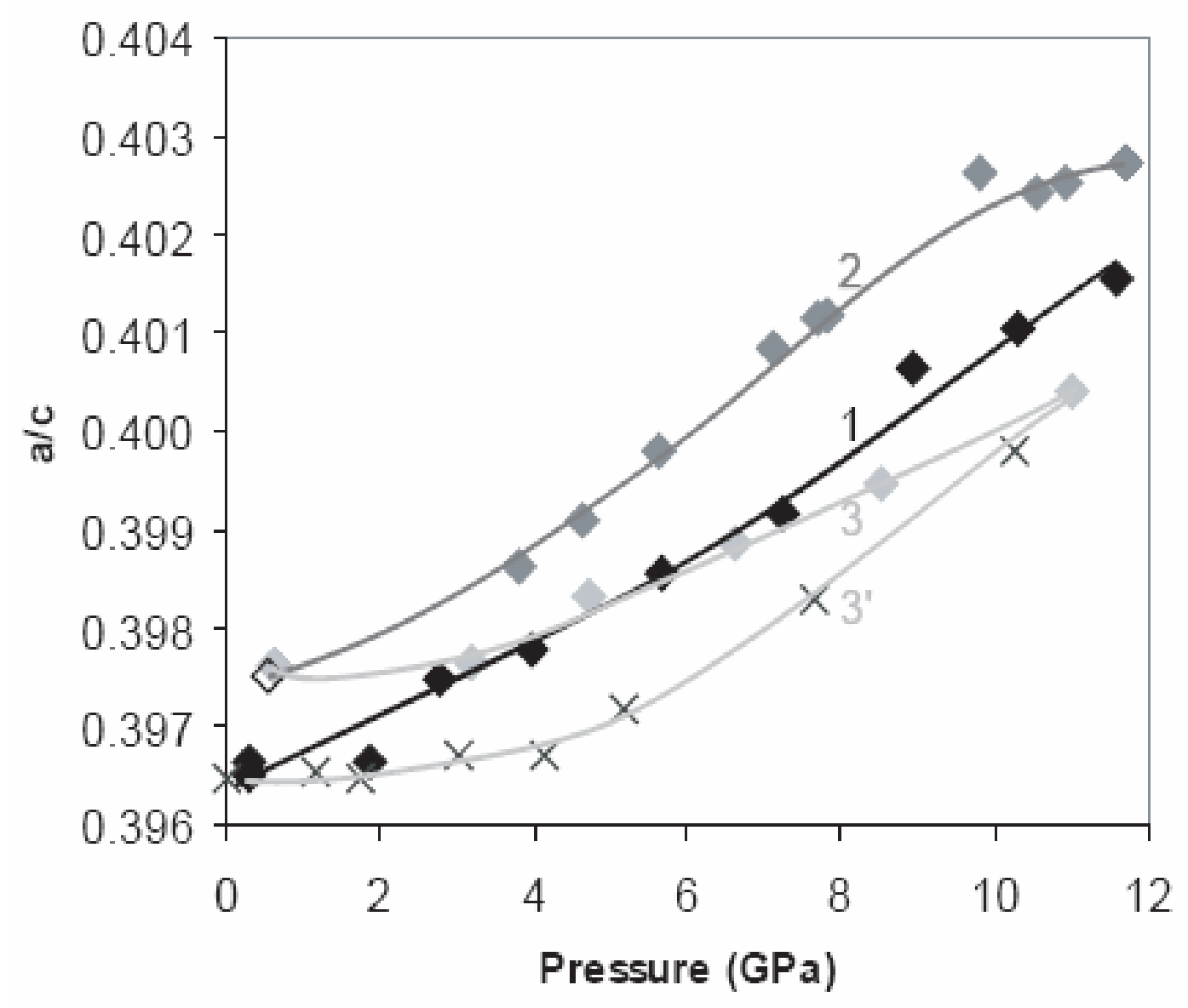


Fig. 4.
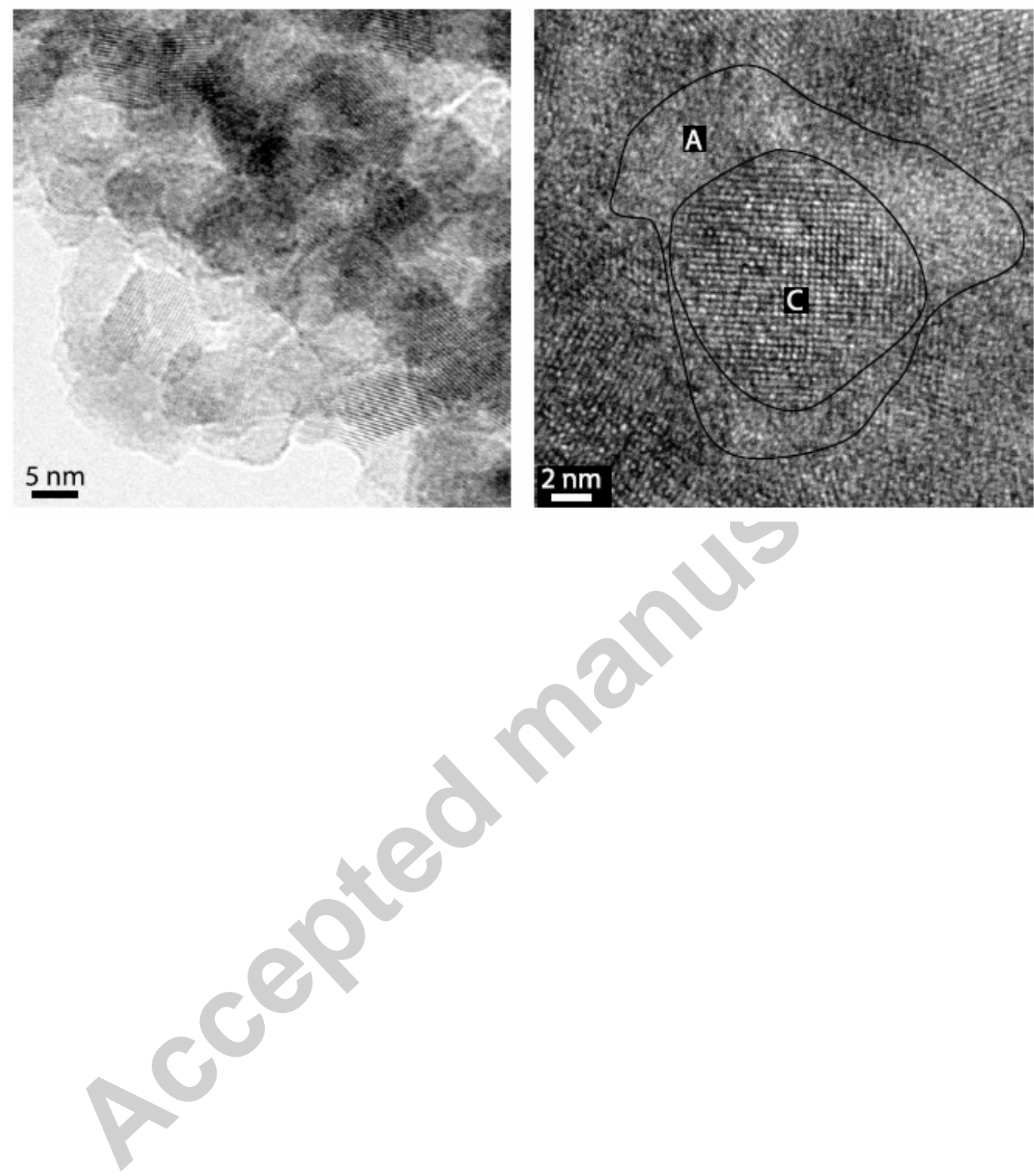